\title{
UMA NOVA MODALIDADE DE SEXO-DETERMINAÇÃO NO GRILO SUL-AMERICANO ENEOPTERA SURINAMENSIS
}

\author{
S. de Toledo Piza Jor. \\ Prof. de Zoologia, Anatomia e Fisiologia \\ Escola Superior de Agricultura "Luiz de Queiroz" \\ Universidade de São Paulo
}

INDICE

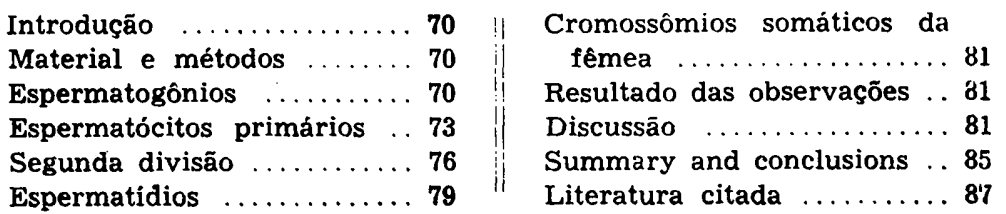




\section{INTRODUÇAO}

Os Ortópteros $\left({ }^{*}\right)$ constituem, sem dúvida, um dos grupos de Insetos mais bem estudados sob o ponto de vista do mecanismo sexo-determinante. A facilidade de se obter material abundante e variado e o tamanho geralmente considerável dos cromossómios fizeram dêles um dos objetos mais apropriados para pesquisas e demonstrações. A espermatogênese tem sido estudada num grande número de espécies filiadas a diferentes familias, achando-se a literatura repleta de trabalhos, notas e comunicaçóes sóbre o assunto. Resultou daf a notável constatação da uniformidade com que o mesmo tipo de sexo-determinação se repete dentro do grupo. Podemos assim dizer, que salvo reduzidas exceçōes, os machos dos Ortópteros são XO e as fêmeas XX. Fogem à regra apenas os Mantideos estudados por OGUMA (1921), KING (1931), ASANA (1934) e WHITE (1941), os Acridídeos estudados por McCLUNG (1917) e por KING \& BEAMS (1938), os Grilóidea estudados por MAKNNO (1932) e por McKLUNG \& ASANA (1933) e os Grilotalpideos estudados por diversos autores (PAYNE 1916, DE WINIWARTER 1927, STEOPE 1939), cujos machos são do tipo sexual $\mathrm{X} 1 \mathrm{X} 2 \mathrm{Y}$ ou $\mathrm{XY}$. Um resumo da queståo até 1928 encontra-se Em SCHRADER.

Conforme veremos ao discutir o assunto, o tipo de sexodeterminação que passarei a descrever é inteiramente novo para os Ortópteros, sobretudo no que se refere ao comportamento dos cromossómios sexuais, não encontrando paralelo mesmo fora da Ordem.

\section{MATERIAL E MÉTODOS}

A espécie estudada no presente trabalho, Eneoptera surinamensis De Geer, pertence à familia Eneopteridae, da superfamilia Grylloidea. Machos e fêmeas foram dissecados sob Ringer, ns testiculos fixados em Allen-Bouin (modificação de Baur) e Flemming forte e os ovários apenas no primeiro dêsses fixadores. Os cortes foram feitos com 10 e 12 micra e coloridos pela hematoxilina de Heidenhain.

\section{ESPERMATOGONIOS}

Os espermatogônios são providos de 9 cromossômios, sendo 6 recurvados em forma de $U$, mais ou menos do mesmo ta-

(*) Considero, por mera comodidade, os Mantídeos incluidos nessa Ordem. 


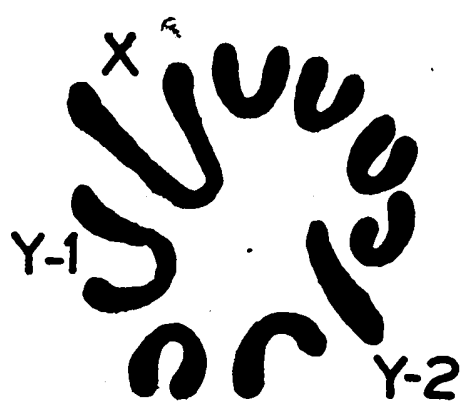

1

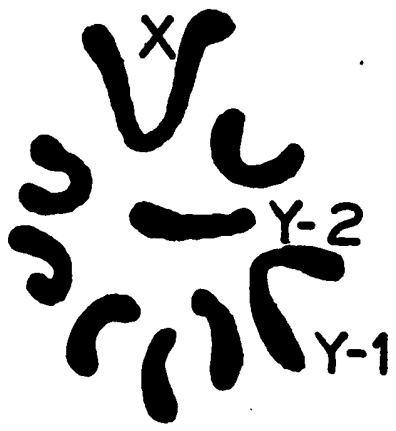

2

Figs. 1 e 2 - Metáfases dos espermatogônios em vista polar. (X 3500).

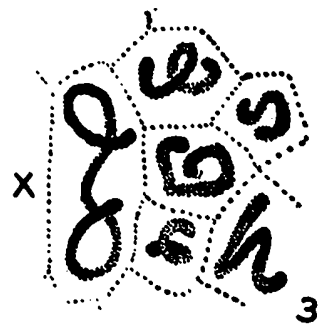

Fig. 3 - Espermatogônio em prófase, vendo-se o cromossómio $X$ e alguns autossômios no interior de vesículas. ( $X$ 2800).
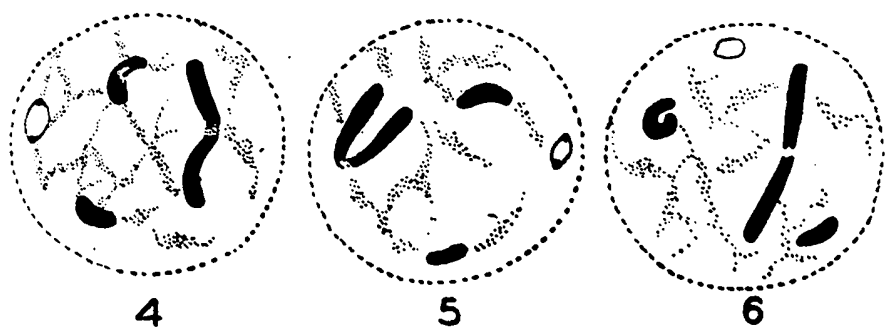

Figs. 4, 5 e 6 - Espermatócitos primários antes do periodo de crescimento, mostrando os três cromossômios sexuais e o plasmossómio. (X 3500). 
manho, um em forma de maça, que se pode apresentar direito ou recudvado, aproximadamente igual aos precedentes, e dois grandes elementos em forma de V, um dos quais é maior do que o outro. (Figs. 1 e 2). Com exceção do cromossomio que tem forma de maça e que é telocêntrico (Y2), todos os outros são mediocéntricos. $\mathrm{Na}$ metáfase os cromossómios se disprem em círculo na placa equatorial, com os vértices geralmente voltados para o centro, porém, aparentemente, sem nenhuma ordem. Dadas a forma e as dimensoes dos 6 elementos menores, torna-se impossivel identificar os membros de cada par, mesmo quando éles se arranjam como na Fig. 1. A posição do cromossómio em maça pode ser qualquer, o mesmo se verificando com os dois elementos em $\mathrm{V}$, que tanto se podem encontrar juntos (Fig. 1), como separados (Fig. 2). No final da metáfase os cromossómios se apresentam inteiramente divididos no sentido longitudinal, sendo frequentes as vistas polares em que se podem notar duas placas simétricas sobrepostas. Em algumas células de cromossómios mais contraidos do que habitualmente, os dois Vs se apresentam quase do mesmo tamanho.

Do meio para o final da prófase os cromossómios se encontram no interior de vesículas de seçáo poligonal e de contornos bem nítidos, parecendo que cada uma é uma pequena célula provida de um único cromossómio. (Fig. 3). Ai eles se apresentam recurvados, torcidos, dobrados e longitudinalmente divididos na maior parte da sua extensão. Nesse período do ciclo espermatogonial o cromossómio correspondente ao $\mathrm{V}$ maior da metáfase sobrepuja enormemente a todos os outros. (X, Fig. 3). As vesículas cromossomais vão perdendo a sua nitidez à medida que a metáfase se aproxima, para entăo se tornarem indistintas.

Os três cromossómios sem parceiros, isto é, os dols elementos em forma de $\mathrm{V}$ e o elemento em forma de maça, podem desde já ser considerados como cromossomios sexuais, pois que teremos disso a confirmaçáo ao estudar o seu comportamento na melose.

Da última telófase espermatogonial para a intercinese os 6 autossomios perdem a sua individualidade, permanecendo, porém, em estado de heteropicnose, os três cromossómios do sexo. (Figs. 4, 5 e 6). Destes, o que corresponde ao $\mathrm{V}$ maior tem dimensőes consideráveis e exibe uma ampla constriçăo primária submediana, podendo apresentar-se dobrado dos modos os mais diversos ou distendido. Dos outros dois, que săo bem menores, o que corresponde ao outro $\mathrm{V}$ apresenta-se geralmente recurvado ou dobrado, ao passo que o terceiro - o correspon- 
dente ao sexo-cromossómio em forma de maça - mostra-se como um espésso e curto bastonete. Um plasmossómio do tipo anfinucleolar acha-se também presente.

\section{ESPERMATÓCITOS PRIMARIOS}

- comportamento dos autossômios durante o período de crescimento do espermatócito é confuso. Nenhuma das fases que precedem ao estado diplotene pode ser analisada com precisão, em virtude da pequena basicidade dos autossómios. Os sexo-cromossómios conservam-se em estado de heteropicnose, sofrendo diferentes modificações. Um dos cromossómios se-
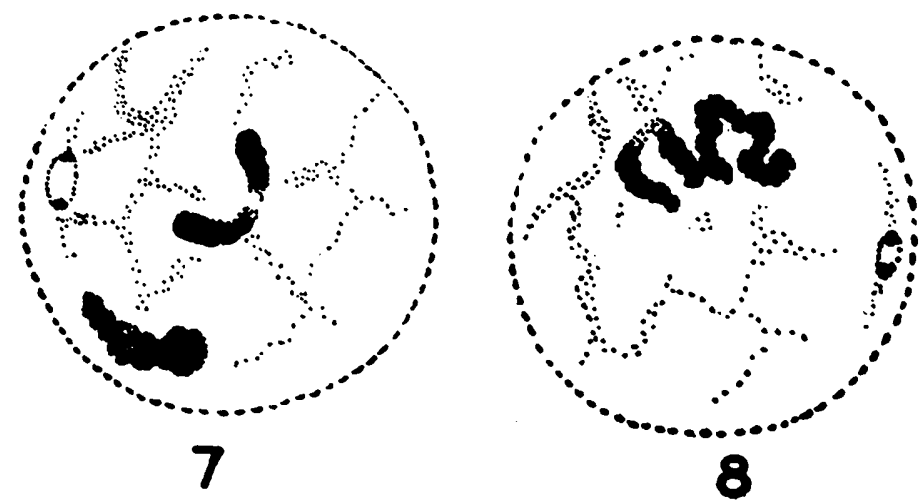

Figs. 7 e 8 - Espermatócitos primários antes da fase diplotene com apenas dois dos sexo-cromossómios em estado de heteropicnose. Em 7 éles estão separados e em 8 unidos pela extremidade. (X 3300).

xuais desaparece e os dois restantes muitas vezes se confundem numa espessa e complicada trama. Porém, mesmo quando presentes em estado individualizado, o que constitui o caso geral, torna-se muito difícil identificá-los com segurança. Um déles se apresenta como um corpo alongado de forma irregular, ora mais denso, ora menos, quase sempre nas proximidade: da membrana nuclear. (Figs. 7 e 9). Também pode apresentarse com uma forma mais ou menos cilindrica e alongada e reeurvado de diferentes maneiras.( Figs. 8, 10, 11 e 12). O outro conserva a forma de $U$ mals ou menos aberto, cujos ramos são licados nor um seqmento eucromático de extensão variável 
umas vezes inteiramente invisível, outras vezes assinalado por alguns grânulos heterocromáticos. (Figs. 7 a 12). Esses dois cromossômios sexuais tanto podem apresentar-se separados (Figs. 7, 9 e 10), como muito aproximados e nesse caso ligados por conectivos heterocromáticos. (Figs. 8, 11 e 12). A ligação pode dar-se pelas extremidades (Fig. 8) ou por diferentes regióes do corpo de ambos. (Figs. 11 e 12).

o anfinucléolo é mais ou menos alongado e em geral se apresenta com os pólos opostos fortemente cromatinizados. Algumas vezes se mostra inteiramente colorido.

Diplotene e diacinese - Nestas fases as cousas tornam-se bem mais claras. Aparecem no núcleo três diplonemas de tipo ortodoxo e três monovalentes que correspondem aos três cromossómios sexuais. (Fig. 13). Embora êstes três últimos elementos possam com facilidade ser reconhecidos, é sòmente com dificuldade que se consegue identificá-los, pois que os três podem se apresentar dobrados ou distendidos, variando a sua espessura. Os dois sexo-cromossômios que se mantiveram sempre visiveis nas fases precedentes, podem mostrar-se, também a.qui, unidos. (Fig. 14). No final da fase diplotene, entretanto, (Fig. 15), e na diacinese, isso se consegue com certa facilidade.

No estado de máxima contraçáo os sexo-cromossômios distinguem-se entre si pela configuração e pelo tamanho. Nessas condições um déles tem a forma de bastonete e os dois outros a forma de V. Nas melhores células um dos Vs mostra-se nitidamente maior que o outro. Em muitas, porém, năo se consegue distinguir um $\mathrm{V}$ do outro, principalmente em virtude das múltiplas posições em que êles se podem apresentar aos olhos do observador, o que impossibilita a comparação.

Metáfase - Nesta fase as tétrades se orientam como de ordinário na placa equatorial, ficando os sexo-cromossómios desorientados, em qualquer posição. Na maior parte das boas figuras representando vistas laterais, o $\mathrm{V}$ maior é encontrado de um lado da placa autossomal e o menor, acompanhado do bastonete, do lado oposto. (Figs. 16 e 18). Em algumas, entretanto, constatou-se a presença tanto do bastonete (Fig. 17), como de qualquer dos Vs, no plano do equador, havendo casos em que os três sexo-cromossómios podem achar-se ao mesmo tempo nesse plano. Raramente os dois Vs foram encontrados do mesmo lado; em oposição ao bastonete. (Fig. 19).

$\mathrm{O}$ cinetocore do $\mathrm{V}$ maior pode se apresentar como uma pe- 
quena protuberância eucromática que se destaca da constrição. (Figs. 31 e 32).

Anáfase - Nas figuras anafásicas sempre se nota o $\mathrm{V}$ maior perto de um dos pólos e o $\mathrm{V}$ menor juntamente com o bastonete perto do outro pólo, porém, bem separados um do outro. (Figs. 20 e 21). Desde muito cedo, autossômios e sexocromossómios se dividem, ficando unidos apenas pelo ponto de inserção. $\mathbf{E}$ como os dois cromatidios resultantes da divisão longitudinal dos Vs podem em alguns casos ficar em perfeita sobreposição e, de outro lado, os cromatídios provenientes da di-
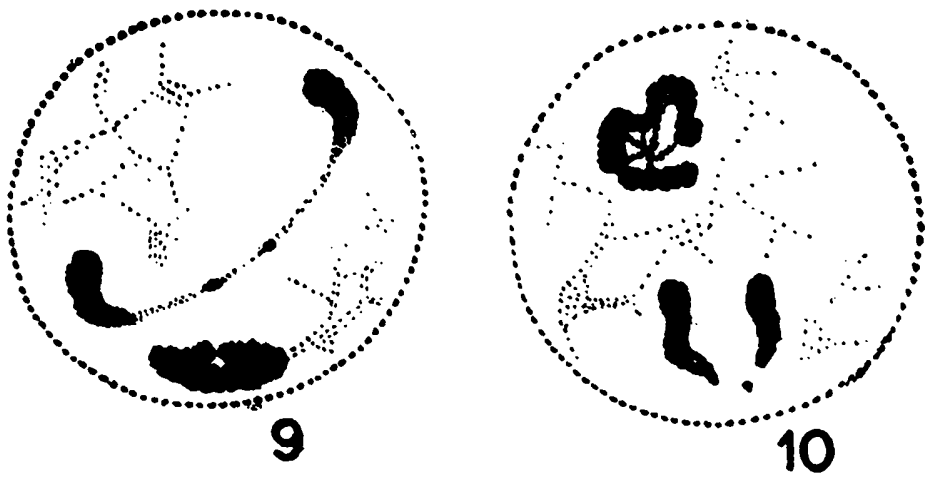

Figs. 9 e 10 - Espermatócitos primários antes da fase diplotene. Em 9 um dos sexo-cromossômios apresenta os seus braços ligados por um longo segmento eucromático em que se notam alguns grânulos heterocromáticos. Em 10 um dos cromossômios sexuais se acha encurvado e diversos de seus pontos ligados por conectivos heterocromáticos e o outro apresenta os seus braços ligados por um segmento invisivel, apenas assinalado por um grânulo heterocromático. (X 3300).

visão do bastonete podem se apresentar em ângulo mais ou menos aberto, ser-se-ia levado a pensar que os dois Vs tivessem passado para o mesmo pólo e isso principalmente nas figuras incompletas. Porém, em tôdas as figuras consideradas boas para estudo, o V maior se encontra na frente de uma das placas anafásicas e o bastonete com o $\mathrm{V}$ menor na frente da outra. Năo fica, entretanto, excluida, como a Fig. 19 sugere, a possibilidade da passagem dos dois Vs para o mesmo pólo e bem assim da passagem do bastonete para o pólo em que se encontra o V maior. 
Telófase - Nas vistas polares da telófase verifica-se que todos os cromossômios têm quatro braços reunidos pelo cinetocore e que se podem apresentar em diferentes posições. Apenas o bastonete se mostra com a forma de V. (Fig. 22).

Autossômios e sexo-cromossômios se vão distendendo e descolorindo e a membrana nuclear se reconstitui sem que o núcleo chegue a entrar na fase de repouso. Os cromossômios, que não tinham perdido a sua forma, entram de novo a se contrair, encaminhando-se para a metáfase da segunda divisão.
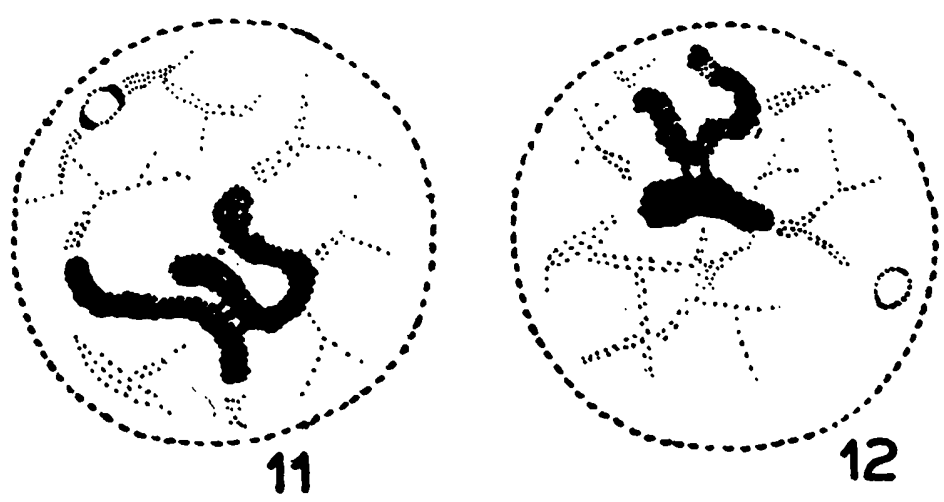

Figs. 11 e 12 - Espermatócitos primários antes da fase diplotene, vendo-se os sexo-cromossômios ligados por diversos conectivos. (X 3300).

\section{SEGUNDA DIVISAOO}

Metáfase - Nas metáfases secundárias se encontram com facilidade espermatócitos de 4 e de 5 cromossómios. Nos de 4 pode-se reconhecer o V maior (Fig. 23) e nos de 5 o bastonete (Fig. 24). Todos os elementos se apresentam unidos apenas pelo cinetocore. O aspecto individual dos cromossómios, porém, depende da posição relativa dos seus braços. As vistas laterais mostram que os cromossômios têm a forma de $\mathbf{X}$, com o cinetocore no plano equatorial.

Anáfase - Nos espermatócitos secundários de 4 cromossómios verifica-se que todos os componentes das placas anafásicas têm a forma de $V$, sendo um dêles bem maior que os demais. Nos de 5 cromossômios reconhece-se em cada placa 


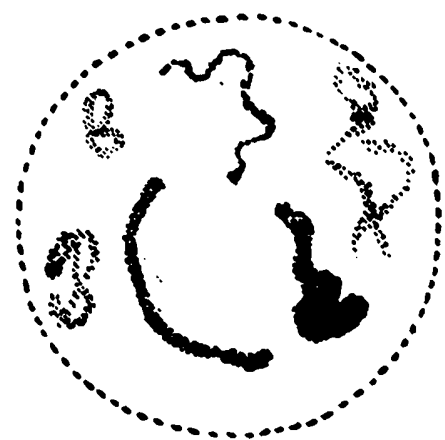

13

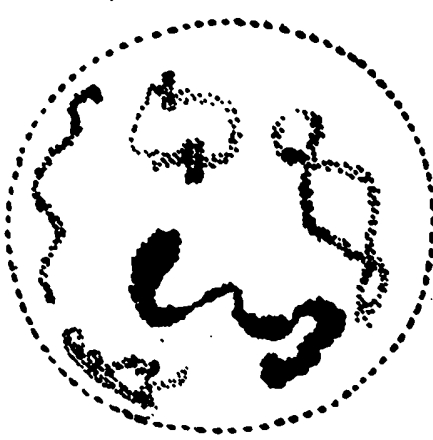

14

Figs. 13 e 14 - Espermatócitos primários em diplotene exibindo 3 tétrades e 3 cromossómios sexuais. Em 13 os sexo-cromossómios estão separados e em 14 dois déles se acham unidos pela extremidade. (X 3300).

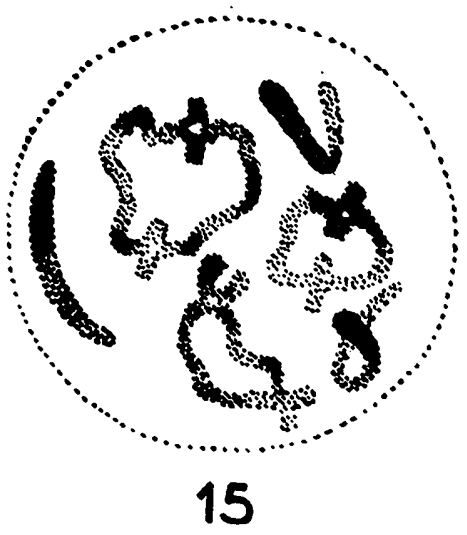

Fig. 15 - Espermatócito primário no final da fase diplotene, com 3 étrades e 3 cromossómios sexuais. (X 3100).

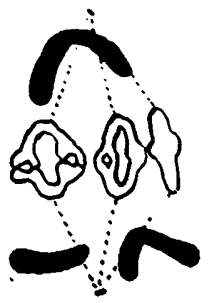

16

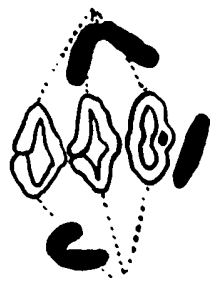

17

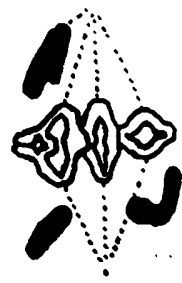

18

Eıgs. 16, 17 e 18 - Vistas laterais da metáfase dos espermatócitos primários. Os sexo-crumossômios em negro. (X22j0). 


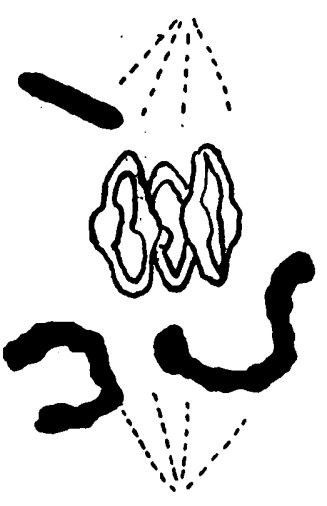

19
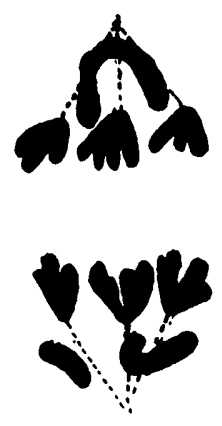

20
Fig. 19 - Vista lateral de um espermatócito primário em metáfase, mostrando os dois sexocromossômios em forma de $\mathbf{V}$ do mesmo lado. ( $X$ 3250).

Figs. 20 e 21 - Espermatócitos primários em anáfase.

(X 3100).

Fig. 22 - Espermatócito secundário em intérfase. $O$ elemento em forma de U corresponde ao sexo-cromossômio em forma de bastonete. ( $\mathrm{X}$ 3800).

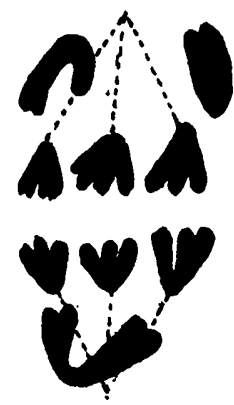

21

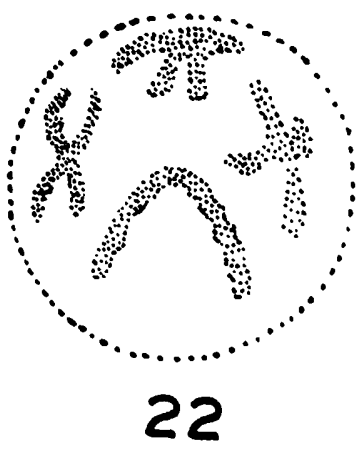


um bastonete e um V maior que os outros três. (Fig. 25). Os cromossômios sexuais podem pois ser reconhecidos também nesta fase da divisăo.

\section{ESPERMATIDIOS}

Após a reconstituição da membrana nuclear os autossómios vão desaparecendo até se sumirem de uma vez. (Fig. 26). Um dos sexo-cromossómios também desaparece dos espermatidios de 5 cromossómios. O resultado é que todos os espermatidios exibem, no interior de um núcleo oticamente vasio em que só se distingue um pequeno plasmossómio, um cromossómio sexual. (Fig. 27). é constituldo por duas metades piri-

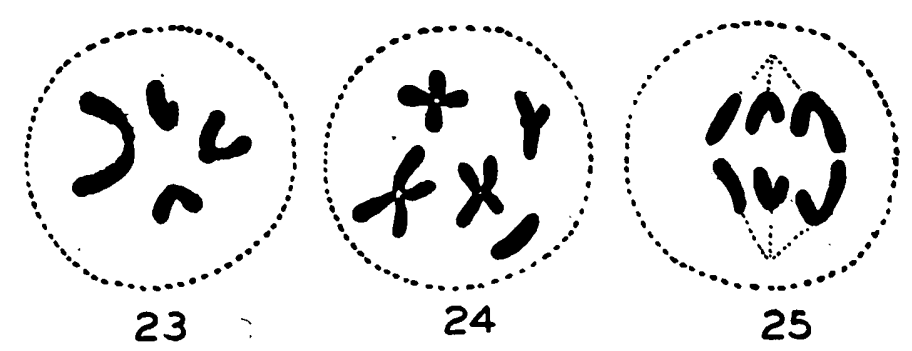

Figs. 23, 24 e 25 - Espermatócitos secundários. 23 - Vista polar do espermatócito de 4 cromossômios, sendo que tanto o sexo-cromossômio como os autossômios apresentam os braços mais ou menos sobrepostos. 24 - Espermatócito de 5 cromossômios, todos, com exceção do sexo-cromossómio em bastonete, com os braços bem separados. 25 - Vista lateral da anáfase do espermatócito de 5 cromossômios, vendo-se à esquerda os bastonetes e à direita os Vs menores. (1200).

formes opostas pela base e se localiza logo abaixo da membranuclear, permanecendo visivel por muito tempo. Embora com a mesma forma em todos os espermatídios, em uns éle corresponde ao $\mathrm{V}$ malor e em outros ao menor. Poucas vezes, em espermatidios mals jovens, foi possivel constatar a presença do elemento correspondente ao sexo-cromossómio em forma de bastonete, o que indica que êsse elemento entra muito ràpidamente em dissoluçáo. (Fig. 28). Multo raramente o cromossòmio sexual pode fragmentar-se pela constrição mediana, o que acarreta confusóes. A presença de um sexo-cromossómio da mesma forma em todos os espermatídios mais evoluldos, năo permite o reconhecimento das duas classes. 


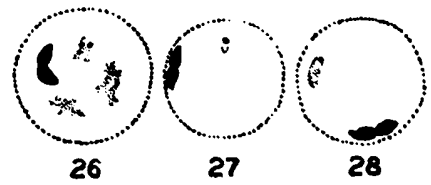

Figs. 26, 27 e 28 - Espermatídios. 26 - Espermatídio jovem, com os autossômios ainda visíveis. ( $X$ 1550). 27 - Espermatídio em que apenas se vê um cromossômio sexual. (X 1650). 28 - Espermatídio com um dos cromossómios sexuais em via de desaparecimento. (X 1350).
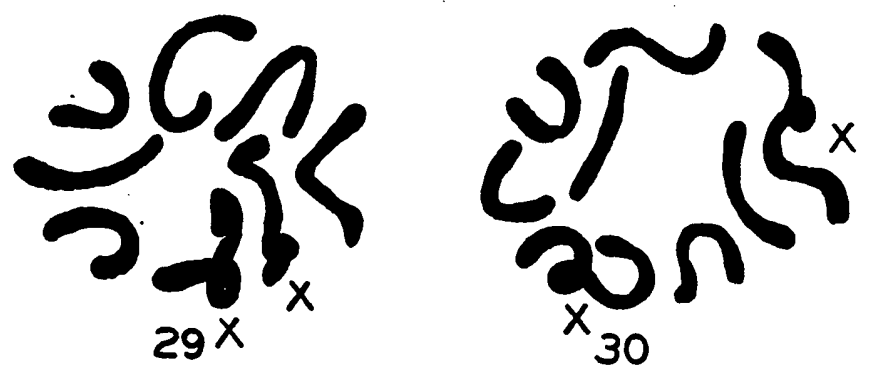

Figs. 29 e 30 - Cromossômios do folículo ovárico. (X 4200).

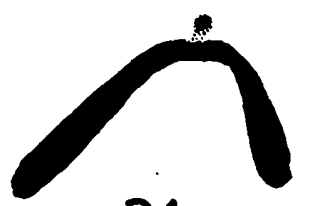

31

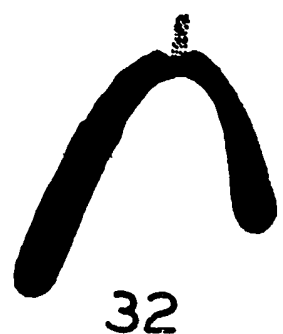

32

Figs. 31 e 32 - o sexo-cromossômio maior mostrando o cinetocore em forma de uma pálida protuberância. (Muito aumentado). 


\section{CROMOSSOMIOS SOMATICOS DA FEMEA}

No folículo ovárico foram encontradas diversas células em metáfase em que os cromossômios puderam ser estudados. A contagem não é fácil, pois muitas vezes êles se apresentam aproximados e em parte sobrepostos. Além disso, a constriçăo primária, ampla e pronunciada, pode levar-nos ao êrro de se contarem como cromossómios distintos os dois braços de um mesmo cromossômio. Poucas foram porisso as células que permitiram uma análise segura. Nestas foram sempre contados 8 cromossomios, dois dos quals são bem maiores que os outros 6 e se apresentam, as mais das vezes, dobrados ou contorcidos das mais variadas maneiras. (Figs. 29 e 30). săo considerados como sendo os cromossómios sexuais. A fémea assim se apresenta, como de regra, provida de um par de sexo-cromossómios.

\section{RESULTADO DAS OBSERVAÇOES}

Os fatos acima descritos levam-me a considerar o macho de Eneoptera surinamensis como sendo X Y1 Y2 e a fêmea XX, sendo $\mathrm{X}$ o elemento que fol considerado como o $\mathrm{V}$ maior, $\mathrm{Y} 1 \mathrm{O}$ $\mathrm{V}$ menor e Y2 o bastonete.

\section{DISCUSSAO}

Os machos dos Ortópteros são em geral do tipo sexual Xo. MCCLUNG (1917) descobriu, porém, alguns Acridídeos dos géneros Hesperotettix e Mermira, cujo mecanismo sexo-determinante passou de $\mathrm{XO}$ a $\mathrm{XY}$ em virtude de uma fusăo do primitivo $\mathrm{X}$ com um autossômio. A heteropicnose sòmente num dos ramos do cromossomio $X$, que tem a forma de $V$, é apontada como prova de que isso de fato se deu. Nesse caso o autossómio homologo daquele que se soldou ao $\mathrm{X}$ ficou sendo o cromossomio Y. (Cf. WHITE 1940). Gryllotalpa vulgaris (Gryllotalpidae) e Oecanthus longicauda (Oecanthidae), estudados respectivamente por DE WINIWARTER (1927) e por MAKINO (1932), que também pertencem ao tipo sexual XY, diferem dos Acridídeos acima referidos, por possuirem o cromossómio $\mathrm{X}$ simples, isto é, năo soldado a qualquer outro elemento, e um $Y$ diminuto, de forma granular.

Já pelo número dos cromossômios sexuais presentes, já pela sua estrutura e pelo seu comportamento na meiose, nenhum 
dos casos que acabei de citar se pode comparar ao de Eneoptera, razão pela qual deixarei de discutí-los aqui.

Um outro tipo de sexo-determinação dos Ortópteros que foge à regra e que é mais complicado que os precedentes é o chamado X1 X2 Y, encontrado em Gryllotalpa borealis (PAYNE 1916), no Acridideo Paratylotropidia brunneri (KING \& BEAMS 1938) e em diversas espécies de Mantideos. Em todos ésses casos há uma tríade de cromossômios sexuais em jôgo. Eneoptera surinamensis, porém, difere dos outros ortópteros providos de três sexo-cromossómios, na maneira dêsses elementos se comportarem na meiose. Assim, Gryllotalpa borealis é único no fato de um dos cromossómios sexuais não entrar em contacto com os dois outros, que se apresentam unidos na metáfase da primeira divisáo. Dos três elementos sexuais, portanto, apenas dois se paream. Em Paratylotropidia e em todos os Mantídeos providos de três sexo-cromossómios (X1 X2 Y) êsses três elementos formam um grupo trivalente na metáfase dos espermatócitos primários, sendo que ambos os Xs (X1 e X2) se unem ao Y. Por ocasiáo da anáfase X1 e X2 vão livremente para um dos pólos e $Y$ para o outro. Em Paratenodera e Sphodromatis WHITE (1941) assinalou um bom número de casos em que tanto $\mathrm{X} 1$ como $\mathrm{X} 2$ deixa de se parear com $\mathrm{Y}$, comportando-se os sexo-cromossómios tal como no caso de Gryllotalpa borealis. Apenas, nos Mantídeos, como era de se esperar, por se tratar de um mero acidente o elemento que fica livre tanto passa para um como para outro pólo, dando origem a espermatócitos secundários contenđo $\mathrm{Y}$ indiferentemente associado 2 $\mathrm{X} 1$ ou a X2. Isso, se de fato não se dá no Gryllotalpideo estudado por PAYNE, como parece, é, provàvelmente, por es tratar de um processo natural de disjunção determinada que se estabeleceu através de uma longa evolução. Entretanto, a possibilidade de uma outra distribuição dos sexo-cromossómios năo fica de todo excluida.

Em todos os Ortópteros até agora estudados cujos machos são providos de três cromossômios sexuais, êsses cromossômios formam um grupo trivalente na metáfase, sendo, pois, a segregação, sempre precedida de um contacto. O único caso de segregação determinada que se conhece é o do Gryllotalpa borealis, no qual apenas dois dos sexo-cromossômios, como foi dito acima, se unem para formar um bivalente, ficando o outro inteiramente livre num dos pólos. Esse caso, porém, não tem absoluta segurança, não só por não estar ainda suficientemente analisado, como por assemelhar-se inteiramente ao caso da Drosophila miranda descrito por DOBZHANSKY (1935), o 
qual, segundo mostraram MacKNIGHT e COOPER (1944), é perfeitamente normal, entrando ambos os Xs em contacto com o $Y$, 1.al como se dá com os Acridídeos e Mantídeos do tipo XI X2 Y. - de se esperar que o mesmo aconteça também com Gryllotalpa borealis, ainda mais, que segundo assinalou MacKNIGHT (1939), uma das figuras de PAYNE mostra conexăo do bivalente desigual ( $\mathrm{X} 1$ e $\mathrm{Y}$ ) com o univalente (X2). Fica desse mndo Eneoptera surinamensis como sendo o único Ortóptero provido de trés cromossómios sexuais, que, sem formarem na metáfase um complexo trivalente ou sequer se aproximarem como se verifica nos Hemipteros, segregam de maneira regular, indo o cromossómio $X$ para um dos pólos e os cromossomios Y1 e Y2 para o outro.

Fora da Ordem Orthoptera só se conhecem duas espécies cujo sexo heterogamético é igualmente do tipo XY1 Y2. Sz̊o elas a Drosophila virilis americana (HUGHES 1939) e o LepIdóptero Noctuídeo Phragmatobia fuliginosa (SEILER 1925). Há, porém, em ambas, formação de grupos metafásicos.

Uma vez que se pode pór em dúvida a segregação determinada de Gryllotalpa borealis, principalmente depois do que fol assinalado por MacKNIGHT (1939), e que na Drosophila miranda, segundo mostraram MacKNIGHT e COOPER (1944), também năo existe segregaçăo determinada, isto é, separaçăo sem prévio contacto, como fóra admitido por DOBZHANSKY, fica Eneoptera surinamensis o representante típico e provàvelmente exclusivo desse enigmático mecanismo de separaçáo dos cromossomios sexuais. $\mathbf{E}$ isso, porque, dos poucos casos restantes, uns sáo muito irregulares, variáveis e confusos para poderem ser analisados e classificados, tal como se dá com o Neuróptero Ascalaphus libelluloides (NAVILLE \& BEAUMONT 1939); noutros, como em Perla (Plecoptera-Perlidae), Syromastes (Hemiptera-Coreidae) e em diversas espécles de aranhas, nzo havendo o cromossómio $\mathrm{Y}$, todos os sexo-cromossómios, unidos por uma afinidade ainda incompreendida, passam para o mesmo pólo e portanto năo efetuam segregaçăo de especie alguma; noutros, finalmente, como nos Nematoides, o material, pela sua natureza, năo permite qualquer conclusăo segura.

O comportamento dos cromossómios sexuais dos Hemípteros providos de um $\mathrm{Y}$ e dois ou mais $\mathrm{Xs}$ pode ser considerado como intermediário entre a segregaçáo precedida de contacto e a segregação determinada, visto que naqueles insetos os sexocromossomios aproximam-se todos entre si por ocasiko da metáfase. 
Comportamento dos sexo-cromossómios de Eneoptera surinamensis. - Os cromossômios sexuais de Eneoptera, no final da diacinese, se distribuem ao acaso na célula, ficando sempre bem separados. Quando o fuso se instala e as tétrades se orientam, $X$ procura alojar-se nas proximidades de um dos pólos, enquanto $\mathrm{Y1}$ e $\mathrm{Y2}$, bem distanciados um do outro, procuram 0 pólo oposto. Em vista disso, na anáfase, êles se apresentam em precessaro, $X$ na frente de uma das placas e os dois Ys na frente da outra. O fato de se haver algumas vezes observado metáfases em que $X$ se encontra de um lado, $Y 1$ do outro e $Y 2$ no plano equatorial ou entāo $X$ e $Y 1$ em oposiçăo a $Y 2$, năo prova que a distribuiçăo final seja diferente daquela que fol descrita, porquanto, antes da anáfase, sempre se pode esperar que os cromossomios sexuais acabem por se colocar nas situaçбes habituais. Entretanto, essas figuras sugerem a possibilidade da passagem de $\mathrm{X}$ e $\mathrm{Y} 1$ ou $\mathrm{X}$ e $\mathrm{Y} 2$ para o mesmo polo. Se isso acontecer, devemos considerar os gametas anormais como sendo inviávels ou dando produtos que se năo desenvolvem.

A unizo de $\mathrm{X}$ com $\mathrm{Y} 1$ observada com bastante frequencia nos estados que precedem a metáfase parece-me destituida de significaçăo especial. Em primeiro lugar porque com igual frequencia esses dois sexo-cromossómios se podem apresentar separados em fases correspondentes e em segundo porque a reuniza se realiza por contacto direto das mals variadas partes de ambos ou por meio de conectivos heterocromáticos identicos àqueles que se observam ligando duas ou mais partes do corpo do mesmo sexo-cromossomio quando êste se apresenta dobrado. Atraçáo de pontos, significando homologia de partes, parece que decididamente năo existe. A aproximação pode ser meramente casual e a uniáo uma simples consquencia do estado físico-químico dos cromossomios. Entretanto, pode-se admitir uma pequena afinidade entre esses dols elementos, capaz de favorecer a sua aproximaçăo e uniăo. Se essa afinidade existe, nada se pode dizer da sua natureza.

Na metáfase parece que năo há repulsăo especial entre os sexo-cromossomios, ficando $X$ ora mais perto de $Y 1$, ora de $Y 2$. $\mathrm{Na}$ anáfase, porém, a repulsăo entre $\mathrm{X}$ e qualquer dos $Y$ s é maior que a repulsăo entre os dois Ys, de sorte que estes ultimos ficam em oposiçăo ao primeiro. Essa repulsăo é uma repulsăo global e desorientada, quer dizer, os sexo-cromossómios que se repelem ficam em qualquer posiçăo.

O sexo-cromossomio Y2 parece năo ter completado ainda a sua evoluçáo, exibindo propriedades de cromossómio sexual e de autossómions. assim que nọ espermatócitọs que văo en- 
trar em período de crescimento êle se mostra tăo heteropicnótico como os dois outros cromossómios, para na prófase da meiose desaparecer inteiramente, tornando-se indistinto como os autossómios. Só mais tarde, quando os bivalentes se deixam distinguir, no estado diplotene, é que ele reaparece.

\section{SUMMARY AND CONCLUSIONS}

The male of Eneoptera surinamensis (Orthoptera-Eneopteridae) is provided with 9 chromosomes, that is, with 3 pairs of autosomes and 3 sex chromosomes.

Spermatogonia. - The autosomes of the spermatogonia are of the same size and U-shaped. One of the sex chromosomes approximately equalling the autosomes in size is telocentric, while the other two are much larger and V-shaped. One of the latter is smaller than the other. The sex chromosomes as showed in Figs. 1 and 2 are designated by $X, Y 1$ and $Y 2, X$ being the larger V, Y1 the smaller one and Y2 the rod-shaped.

Primary spermatocytes. - Before the growth period of the spermatocytes all the three sex chromosomes are visible in a state of strong heteropycnosis. $X$ is remarkable in this stage in having two long arms well separated by a wide commissural segment. (Figs. 4, 5 and 6). During the growth period Y2 disappears, while $X$ and $Y 1$ remain in a condensed form until metaphase. These may be separated from one another or united in the most varied and irregular manner. (Fig. 7 to 12). In the latter case the segments in contact seem to be always different so that we cannot recognize any homology of parts in the sense os genetics.

At diplotene $\mathrm{Y} 2$ reappears together with the autosomal tetrads. $X$ and $Y 1$ may again be seen as separate or united elements. (Figs. 13 and 14). At later diakinesis and metaphase the three sex chromosomes are always independent from each other, $Y 2$ being typically rod-shaped, $X$ and $Y 1$ V-shaped, $X$ being a little larger than Y1. (Fig. 15 to 18).

At metaphase the three condensed tetrads go to the equatorial plane, while the sex chromosomes occupy any position at both sides of this plane. In almost all figures which could be perfectly analysed $X$ appeared at one side of the autosomal plate an Y1 together with Y2 far apart at the other side. (Figs. 16 and 18). Only a few exception have been found. (Figs. 17 and 19). 
At anaphase $X$ goes in precession to one pole, $Y 1$ and $Y 2$ to the other (Figs. 20 and 21). As it is suggested by the few figures in which a localization of the sex chromosomes different from the normal has been observed, the possibility of other types of segregation of these elements cannot be entirely precluded. But, if this does happen, the resulting gametes should be inviable or give inviable zygotes.

Early in anaphase autosomes and sex chromosomes divide longitudinally, being maintained united only by the kinetochore. (Figs. 20 and 21).

At metaphase the three sex chromosomes seem to show no special repulsion against each other, $X$ being found in the proximity of $\mathrm{Y1}$ or $\mathrm{Y2}$ indifferently. At anaphase, however, the evidences in hand point to a stronger repulsion between $X$ on the one side and both Ys on the other, so that in spite of the mutual repulsion of the latter they finish by going to the same pole.

Secondary spermatocytes. - At telophase of the primary spermatocytes all the chromosomes enter into distension without disappearing of view. A nuclear membrane is formed around the chromosomes. All the chromosomes excepting Y2 which has two arms, are four-branched. (Fig. 22). Soon the chromosomes enter again into contraction giving rise to the secondary metaphase plate. Secondary spermatocytes provided as expected with four and five chromosomes are abundantly found. (Figs. 23 and 24). In the former all chromosomes are $\mathrm{X}$-shaped while in the latter there is one which is V-shaped. This is the rod-shaped Y2. In the anaphase of the spermatocytes with four chromosomes all the chromosomes are V-shaped, one of them ( $X$ ) being much larger than the others. In those with five there is one rod-shaped chromosome (Y2). (Fig. 25).

Spermatids. Two classes of spermatids are produced, one with $\mathrm{X}$ and other with $\mathrm{Y} 1$ and $Y 2$. All the autosomes as well as $Y 2$ soon enter into solution, $X$ remaining visible for long time in one class and $Y 1$ in the other. (Figs. 26 and 27). Since both are very allke at this stage, one cannot distinguish the two classes of spermatids.

Somatic chromosomes in the famale. - In the follicular cells of the ovary 8 chromosomes were found, two of which are much larger than the rest. (Figs. 29 and 30). These are considered as being sex chromosomes. 
Conclusion - Eneoptera surinamensis has a new type of sex-determining mechanism, the male being $X$ Y1 $Y 2$ and the female $\mathrm{XX}$. The sex chromosomes segregate without entering into contact at metaphase or forming group. After a review of the other known cases of complex sex chromosome mechanism the author held that Eneoptera is the unique representative of a true determinate segregation of sex chromosomes. Y2 behaving as sex chromosome and as autosome is considered as representing an intermediary state of the evolution of the sex chromosomes.

\section{LITERATURA CITADA}

ASANA, J. J. 1934 - Studies on the chromosomes of Indian Orthoptera. IV. The idiochromosomes of Hierodula sp. Cur. Sci. 2: 244-245.

DOBZHANSKY, Th. 1935 - Drosophila miranda, a new species. Genetics 20: 377-391.

HUGHES, R. D. 1937 - The chromosomes in the hybrid bet,ween Drosophila virilis virilis and Drosophila virilis americana Spencer. Genetics 24: 99.

KING, R. L. 1931 - Chromosomes of three species of Mantidae. J. Morph. 52: 523-533.

KING, R. L. \& H. W. BEAMS 1938 - The multiple chromosomes of Paratylotropidia brunneri Scudder (OrthopteraAcrididae). J. Morph. 63: 289-299.

MacKNIGHT, R. H. 1939 - The sex-determining mechanism: of Drosophila miranda. Genetics 24: 180-201.

MacKNIGHT, R. H. \& K. W. COOPER 1944 - The synapsis ot the sex-chromosomes of Drosophila miranda in relation to their directed segregation. Proc. Nat. Ac. Sci. 30: 384-387. 
MAKINO, S. 1932 - An unequal pair of idiochromosomes in the tree-kricket Aecanthus longicauda Mats. J. Fac. Sci. Hokk. Univ. Ser. VI, 2: 1-35.

McKLUNG, C. E. 1917 - The multiple chromosomes of Hesperotettix and Mermira. J. Morph. 29: 519-605.

MCLUNG, C. E. \& J. J. ASANA 1933 - The chromosomes of Schizodactylus monstruosus. J. Morph. 55: 185-191.

NAVILLE, A. \& J. de BEAUMONT 1933 - Recherches sur les chromosomes des Névroptères. Arch. Anat. Microsc. 29 : 199-243.

OGUMA, K. 1921 - The idiochromosomes of the Mantis. J. Col. Agric. Sapp. 10: 1-27.

PAYNE, F. 1916 - A study of the germ-cells of Gryllotalpa borealis and Gryllotalpa vulgaris. J. Morph. 28: 287-327.

SCHRADER, F. 1928 - Die Geschlechtschromosomen. Borntraeger, Berlin. VI-194 ps. 43 fgs.

SEILER, J. 1925 - Ergebnisse aus Kreutzungen von Schmetterlingsrassen mit verschiedener Chromosomenzahl. Arch. Klauss. Stift. Vererb. Forsch. 1: 63-117.

STEOPE, I. 1939 - Nouvelles recherches sur la spermatogenèse chez Gryllotalpa vulgaris de Rumanie. Arch. Zool. Exp. Gén. 80: 445-464.

WHITE, M. J. D. 1940 - The origin and evolution of multiple sex-cromosome mechanisms. J. Genetics 40: 303-336.

WHITE, M. J. D. 1941 - The evolution of sex chromosomes. I. The $X O$ and $X 1 X 2 Y$ mechanism inp raying Mantids. J. Genetics 42: 143-172.

WINIWARTER, H. de 1927 - tude du cycle chromosomique chez diverses races de Gryllotalpa. Arch. Biol. 37 : 515-57!. 